\title{
Language, Cognition and Social Class: A Correlational Study of Social Class and Syntactic Development of Pakistani EFL Learners
}

\author{
Ubaidullah Khan ${ }^{1} \&$ Samina Amin Qadir ${ }^{2}$ \\ ${ }^{1}$ National University of Modern Language, Islamabad, Pakistan; Taif University, KSA \\ ${ }^{2}$ Fatima Jinnah Women University, Rawalpindi, Pakistan \\ Correspondence: Ubaidullah Khan, English Language Center, Taif University, Kingdom of Saudi Arabia, KSA. \\ E-mail: ubaidkhan81@gmail.com
}

$\begin{array}{lc}\text { Received: March 7, } 2018 \quad \text { Accepted: April 5, } 2018 \quad \text { Online Published: May 23, } 2018 \\ \text { doi:10.5539/ijel.v8n5p94 } & \text { URL: https://doi.org/10.5539/ijel.v8n5p94 }\end{array}$

\begin{abstract}
This study aims to find out correlation between social class and the cognitive development of syntax among EFL learners of three Pakistani universities. It focuses on the debate of language being a cognitive or social phenomenon and explores the nature of relationship between the social class of the learners and their cognitive development of syntax. In doing so, it explains how language is not only a cognitive process, but also has something to do with social background of the learners. The research uses a socio-economic index to measure social class of the learners and a test to measure syntactic skills of the learners. Both are assigned equal marks. Correlational study of the scores obtained by the participant in the index and the test reveal moderately significant positive correlation between social class of the participants and their cognitive development of syntax.
\end{abstract}

Keywords: social class, cognitive development, social background, syntactic development, social cognition, socioeconomic status

\section{Introduction}

There is a great debate whether language is a cognitive or a social phenomenon. Cognitivists view language as purely a cognitive phenomenon whereas sociolinguists feel that linguistic development needs to be understood in the light of its relationship with social factors such as social class, race, gender, ethnicity, and so on, and yet others are interested to study how social factors such as social class have a relationship with the development of linguistic cognition. Psycholinguists consider language a cognitive construct, whereas sociolinguistics deem it a socially constructed phenomenon believing that language is a part of human lives and must, therefore, be studied in the light of its relation to society.

Cognitivists believe that language is developmental in nature and develops in cognition slowly and gradually like other cognitive processes such as thinking, understanding, memory and problem solving. According to them, human mind slowly absorbs linguistic input, processes it, and then puts it to use for communication purposes. Johnson (2010), in his discussion of Piaget's theory of cognitive development explains that 'cognitive development is a continual process of building knowledge ... and existing knowledge structures' (p. xiii). The process of learning a second language follows the same cognitive development / information processes in which information about language and language use is "picked up by the senses, stored, coded, and subsequently used in various ways" (Niesser, 2009). The stages of storing the information, coding, and making them ready to be used are very complex and can be understood by keeping in mind various factors that affect cognitive development. Cognitivists rely on Chomskian view of linguistic development who believed that "everybody learns a language ...because they possess an inborn capacity which permits them to acquire a language as a normal maturational process. This capacity is by definition universal..." (Wilkins, 1976, pp. 168-169). He highlighted human ability of "creativity" by which he meant "...the ability of human beings to produce and comprehend an infinite number of novel sentences.” (Al-Jasser, 2012, p. 6).

The above discussion brings us to the understanding that in order to understand linguistic development among learners, we need to look at different aspects of it, and try to look into different influences on it. Looking at language from either sociolinguistic or psycholinguistic perspective may not help us to reach a clear 
understanding of how cognitive and social aspects of language go side by side. To do so, there may be a need to take a different approach to the study of language, which may not take language as purely cognitive or as a purely social phenomenon, and this approach has been termed by Christiansen \& Dirven (2008) as Cognitive Sociolinguistics.

\subsection{Purpose of the Study}

Based upon the approach of study of linguistic development taken by Christiansen \& Dirven (2008), the present study intends to investigate the influence of social class, which is one of the social factors affecting language development, on cognitive development of syntax. In doing so, the study aims to bridge the gap between the traditions of sociolinguistic variationism and cognitive linguistic tradition which study language from social and cognitive perspective, respectively. This study will account only for the link between social class of EFL learners in Pakistani universities and their performance in a syntax-based test. It will study correlation between social class, which is one of the axes of social division, and syntax, which is one of the areas of language that can potentially exhibit varying degree of development among the EFL learners coming from different social backgrounds. The assertion that the development of syntax is "cognitive" in nature, and that the cognitive development of syntax is under the influence of social class, is based on the theories that suggest that development of language is a cognitive process, and the ones that suggest that all cognition is social (Howard \& Renfrow, 2006; Condor \& Antaki, 1997; Marton, Abramoff, \& Rosenzweig, 2005; Overwalle, 2009).

\subsection{Statement of the Problem}

Learners of English as a Foreign Language in Pakistan exhibit varying degree of linguistic development despite the fact that they have received same amount of target language input in form of classroom teaching. Difference of linguistic development is exhibited through varied development of vocabulary, morphology, phonology and syntax. Incomplete or varied development of the above mentioned four areas of language among the learners point to the fact that the students' cognitive development is varied. Syntax, being one of the affected areas, shows significantly varied levels of development too. This difference in students' linguistic development in general and syntactic development in particular leads to various problems faced by the teachers in the classroom. Because the students come from various social backgrounds, a need is felt to study the relationship between students' socio-economic background and the development of their syntactic skills to make sense whether this varied linguistic development is merely due to individual differences or has something to do with their socioeconomic background as well.

\subsection{Objectives}

The present research aims to

i. explore the relationship between social class of the Pakistani EFL learners and cognitive development of syntax among them

ii. find out the extent of variance in syntax-based test vis a vis social class of the Pakistani EFL learners

\subsection{Research Question}

The present research is based on the following research question:

Is there a positive correlation between social class of the learners and cognitive development of syntax among them?

\subsection{Hypothesis}

Based on the above research question, hypotheses of the study could be as follows:

There is a significant relationship between the social class of the EFL learners in Pakistan and their cognitive development of syntax.

\subsection{Delimitation of the Study}

The present study is delimited to the students' performance in the syntax based test, and hence, does not take into account other areas of language such as morphology, phonology or vocabulary etc. It is limited to three universities of Islamabad, the Capital of Pakistan. In terms of sample selection, the study is delimited to the learners whose mother tongue is Punjabi in order to control the intervention of L1 on their performance in syntax test.

\section{Literature Review}

There is a wide array of literature that might help us understand the areas relevant to the present study. Cognitive 
development, language and society, social cognition, social class, and syntactic development are some of the important areas which are directly relevant to this study, and there is a need to go through the literature to make sense of the topic this study intends to investigate. Furthermore, to set a context for this study, various aspects need to be understood thoroughly and clearly. Firstly, it is important to understand how language is linked to society and how the latter has been seen as an influence on linguistic variation. Secondly, there is a need to study whether there is a link between social class of the learners and their academic achievement or not. And thirdly, it needs to be seen whether the same kind of link is evident between social class of the learners in their linguistic development or not. The following sections highlight the areas of discussion hinted at above:

\subsection{Language and Society}

Sociolinguistics as a discipline has been interested to study language in relation to society. Variationist sociolinguists covered the issue of interaction of language with society as they tried to explore how social stratification impacts various aspects of language (Labov, 1972; Juchem, 2003; Mather, n. d.). Social constructionism provides the basis of this idea as its proponents believe that lives of the individuals are constructed under the influence of our social selves. Studies of language variation in sociolinguistics, in the same way, try to make a link between the social selves of the individuals and the kind of language they speak. The differences of language used by the individuals are thus believed to be the representation of the contexts that have gone into the making of the social selves of the individuals.

Although the focus of the study is to look for social class as a correlate of syntactic variations among the students, it is pertinent that an understanding of social stratification and social class is also reached so that the issues related to its correlation with academic achievement in general and with syntactic development in particular become clearer at later stages of the study.

\subsection{Social Class and Language}

We have discussed that there is a correlation between SES of parents and the academic achievement gap among the children. On the basis of this finding, we can believe that there is a likelihood of correlation between the family SES and the linguistic development of children. This assumption of correlation between a family's socioeconomic status and the linguistic development of children has led so many researchers to carry out studies of sociolinguistic variation among the language learners. Their purpose was to see how much social factors affect their linguistic development.

Based on the code theory of Bernstein, variationist sociolinguistic studies have been interested to find out how much effect social class of the individuals has on the kind of language they speak and how social class and linguistic variation correlate (Labov, 1966, 1972; Trudgill, 1974, as cited by Botha, 2011). Bernstein suggests that distinct forms of spoken language are associated with certain social groups. He points out that social groups can be distinguished on the basis of their forms of speech as each has a distinct form, separate from that of the other. He identifies that "the two distinct forms of language use arise because the organization of the two social strata is such that different emphases are placed on language potential" (p. 271).

The same point is extended by other researchers too, in their respective studies. The kind of language the individuals speak, may, in the words of Coloma \& Aires (2010), be "a "marker" of a particular social or income class" and may be a valuable finding from sociolinguistic point of view. Apart from that, Labov (1946) also studied phonological differences in his famous study of departmental stores, in which he found out that people belonging to different social classes have different pronunciation of certain sounds.

\subsection{Cognition, Social Class and Syntax}

The centre of debate in this study is the relationship of language not only with society but also with cognition. For this purpose, there is a need to study the relation of language with both, as well as discuss the idea of social cognition, which might help us develop an understanding of language as a socio-cognitive phenomenon rather than purely cognitive or social one.

Firstly, Piaget (1896-1980) considered that both language and cognition developed because of genetic epistemology. He thought that something in the nature of the infants is there that guides them to the development of language and cognition. As opposed to this theory, Vygotsky believed that for cognition to develop, it was essential that there be an interaction of child with the world around him (as cited in Newman \& Holzman, 2005). Hence, as cognition develops in interaction with society, it is understood as social cognition. This view of looking at cognitive development of language from social perspective is also supported by Christiansen \& Dirven (2008) who emphasise that Cognitive Linguistics needs to adopt an approach that "would bring the objects of study and the methodologies employed in sociolinguistics and Cognitive Linguistics closer together" 
(p. 1). Also, they point out that the researchers have taken important steps towards "an empirically validated investigation into the social dimensions of linguistic variation" (p. 1).

Many researches consider the development of syntax in human brain as a cognitive process. Since language evolves as general human cognition evolves, syntax, being a component of human language, it is to be taken as a cognitive construct. One main theory that supports this view is presented by innatists, who, according to the review of Chomsky (1968, 1980), Bickerton (1990), Pinker \& Bloom (1990), and Pinker (1994) presented by Schoenemann (1999) in Callary (2009) insist that "there is an innate cognitive structure unique to human language ... that determines what sort of basic structures and processes will be reflected in the syntax of any human natural language" (p. 5).

The justification for studying syntax in relation with social class is found in Labov (1946) who studied the phonological variation vis a vis social class of the participants of his study. Further, the suggestions of the syntax being a cognitive process (Callary, 2009) and the ones regarding influence of social factors such as social class on the development of cognition (Olson \& Dweck, 2005, Hahn \& Gawronski, 2008, Payne \& Gawronski, n.d), and on the development of syntax (Vasilyeva, Waterfall, \& Huttenlocher, 2008) make it a case worth studying as to how much social class really correlates with cognitive development of syntax. Linguistic behaviour of the speakers belonging to different social classes is believed to be regular in the sense that a systematic correlation is found between the social factor and the linguistic choices of the speakers (Callary, 2009, p. 5). The present study also extends Bernstein's suggestion that the forms of individual speech habits are socially determined and "they are general and specific as they permeate the entire speech community and exert a considerable influence on the individual speaker" to the study of manifestation of social characteristics in the choice of syntactic options the individual speakers (as cited in Callary, 2009, p. 6). A small scale study of variation of syntax along the lines of social class of the speakers was carried out by Callary who used "A Psycholinguistic Model of Syntactic Maturity" to study the grammatical operations of addition, deletion, substitution, transposition and embedding. Through the study of mean and standard deviation, he found out that the "speakers in high status group are more variable than those in the low social groups" (p. 11) and the speakers of low status group are consistent in selecting syntactic items and processes. He suggested a more sophisticated analysis of the syntactic performance and calls his own study "only a very crude beginning".

After having discussed how language or syntax have been termed as cognitive processes and at the same time are considered to have relationship with social class, there does emerge a case to study language as a socio-cognitive phenomenon rather than purely a cognitive or a social phenomenon, because the theory of social cognition puts a serious question mark on the respective assumptions of language developing in either cognition or in social context. It rather invites attention of the researchers to study it as a social cognitive phenomenon, which is exactly what the present study will endeavor to do.

\section{Research Methodology}

As explained earlier, this research tries to explore whether the students belonging to different socio-economic backgrounds have different linguistic development or not. In this way, the study tries to find out the presence of absence of a link between the social background of the learners and their syntactic development. It is intended to be a quantitative research. The purpose of choosing quantitative method for this research is to measure the socio-economic background of the learners in as reliable way as possible, and to make it replicable for future researchers who might be interested to try to use it in a similar study. It is important to note here that a correlational study does not intend to prove a causal relationship between the variables under investigation, and is limited only to finding out a possible correlation.

Details of quantification of social class and syntax will be presented in the research tools section ahead. But before that it is important to understand the theoretical framework that works as a conceptual guideline for this research.

\subsection{Theoretical Framework}

Hruschka et al. (2009) discuss a new framework of linguistic analyses which considers language as a dynamic phenomenon which is both cognitively and socially informed. They discuss the process of language change and opine that selection of linguistic variants by the users is governed by both social and cognitive constraints. In their view, these approaches emerged with the understanding that "language change [is] as a dynamic population- based process, whereby speakers choose variants from a pool of linguistic variation in a way that is governed by both social and cognitive constraints" (p. 464). Such an approach gave rise to Cognitive Sociolinguistics as a discipline. The roots of such conceptions of language, be they in the realm of language acquisition or language change or variation, can be traced back to social constructionism which is explained by 
Lock \& Strong (2010) in the following lines:

we are not just individually encapsulated information processors, but are inherently social beings who go through a remarkable process of becoming enculturated adults and experience the world in all its glories and disappointments: simply put, we are humans who are constructed through our inherent immersion in a shared experiential world with other people (p. 5).

Considering meaning and understanding as core features of human activity, social constructionism raises the question that how is it that symbolically based language provides an altogether different social experience to two people speaking the same language as compared to two people speaking different language. Meaning and understanding is reached on the basis of mutual consensus over what the symbolic forms mean. Meaning making, then, is embedded in socio-cultural processes which are specific to particular time and place (pp. 6-7). Lock \& Strong (2010) give example of the word fashionable which may mean different in different times, that is, when we compare its meanings in 1900 with those in 2000 and in different space when we compare someone being fashionable in United States of America and in Saudi Arabia.

Examples of the methods used in variationist sociolinguistics can be found in the foundational studies by Labov $(1963,1966,1972)$ who focused on sociolinguistic variation in the field of phonology, in which two variables were believed to be different only in their social or stylistic value, and served the same communicative purpose. Amid the realization that identification of syntactic variables is more difficult than the phonological ones on account of the latter being "easily delimited and recognizable in that they are discrete unites with high frequency of appearance" (Serrano, 1998, p. 1054), many researchers (e.g., Sankoff, 1973, Codergen \& Sankoff, 1974; Weiner \& Labov, 1983) extended the methods to other sociolinguistic variables to levels of grammar other than phonology (as cited by Serrano, 1978, p. 1056). However, Serrano concludes that on the basis of Cheshire's study, it can be concluded that it is "useless to extend the variable rule to the study of syntax" (p. 1057). He argues that the syntactic variable is different from phonological variable in the sense that it depends upon the context of its use and it is up to the researchers to decide whether the syntactic variables correlate with social factors and can be termed as sociolinguistic variables or not. This argument also provides rationale for the present study, which endeavours to do exactly what has been recommended by Serrano, that is, to look for the influence of social factors on the syntactic variables, or otherwise.

\subsection{Method of Research}

The present research studies correlation between social class of the EFL Learners of Pakistani universities and cognitive development of syntax among them. In order to find out relationship between social class of these learners and syntactic development among them, correlation was the most suitable research method. The insight for a correlational study as this one has been taken from Mallinson (2007) who hints at a "patterned relationship" between social class and language variation and advocates for following a method of using a scale to measure the social class to which an individual belongs. She advocates using socio-economic index (SEI) that accounts for the years of education of the person, the occupation of the family head, and the family income. She recommends that the data obtained by this index could be converted to score that could be used to measure an individual's socio-economic standing.

\subsection{Population \& Sample}

Male and female students of English language courses at the universities of Pakistani capital, Islamabad, namely National University of Modern languages, International Islamic University, and Air University, Islamabad constituted population for the present study. These students come to these language courses after having done at least Intermediate, or graduation. They have received at least three months of input in form of classroom teaching in their respective language classes. Purposive sampling was done in order to induct the sample, and the data was collected from ten per cent of the population from each university. The total sample for the study consisted of 82 learners.

\subsection{Research Tools}

For data collection, two tools were designed to measure social class of the participants and their syntactic development, that is, Socio-economic Index (SEI) and Syntax-based Test, respectively.

\subsubsection{Socioeconomic Index}

The Socio-economic Index (SEI) was designed to measure social class of the participants. The data was collected about the students, their fathers and mothers, and the individual's score about these family members was divided over 3 in order to obtain individual's SES score. The SES Index consisted of five factors, namely, monthly income, occupation, educational qualification, medium of instruction, property. Each of these factors was 
divided into three levels and each level was assigned marks. The marks were calculated according to the levels the subjects of the study selected about themselves, their father and mothers. The obtained data was divided over 3 to get an individual's social class score. The way the score was calculated has been explained in the table below:

Table 1. Steps in calculating SES score

\begin{tabular}{ll}
\hline Descriptives & Figures \\
\hline Total variables $x$ score of each variable $=100$ & $5 \times 20=100$ \\
$100 \times 3$ (self, father \& mother) $=300$ & $100 \times 3=300$ \\
Average / Cumulative Class Score: $300 / 3$ & $300 / 3=100$ \\
\hline
\end{tabular}

\subsubsection{Syntax-Based Test}

The syntax-based test aimed to test various syntactic skills of the participants of the study. It was designed in the light of the suggestions given by Callary (2009) and Moravcsik (2006). It included 10 questions carrying a total of 100 marks. The questions tested more than one syntactic skills and hence aimed to avoid possible bias because of the participants' understandings of a particular type of sentence skill. The skills that were tested include constituent replacement (Q. 1), unscrambling sentences (Q. 2), filling in the blanks (Q. 3), rewriting sentences omitting certain words (Q. 4), rewriting sentences replacing certain words (Q. 5), choosing correct sentences from the given options (Q. 6). Question 7 required the participants to make appropriate grammatical choices, lexical choices, verb form choices, pronoun choices, preposition choices, and conjunction choices. Question 8 was about arranging given phrases, question 9 was about correcting the sentences, and Question 10 was about using discourse markers in a the given paragraph.

\section{Data Collection and Analysis}

The data were collected from three universities of Islamabad. The responses of the participants in the SEI about themselves, their father and mothers were converted into score and the score was studied for correlation with the participants' score in their syntax based test. Social Class score was treated as independent variable and syntax was treated as dependent variable. The data was entered into SPSS and correlation and regression were run to obtain results to see how much social class correlates with the syntax score of the participants and how their syntactic development explains cognitive development among them.

\subsection{Correlation and Regression of Social Class Score and Syntax Score}

Correlation analysis is used to describe the strength and direction of the linear relationship between two variables. It, however, does not imply that any kind of causal relationship exists between the two variables. For example, in case of this study, correlation does not imply that the syntax score is influenced by or is a result of the social class of the participants of the study. It is just an analysis of how they correlate with each other, that is, that one exists at the same time as the other does, not because of it or under influence of it.

In order to find out the correlation, normally Pearson correlation coefficient method is used. The effect size in the correlation table is represented through " $\mathrm{F}$ ". It is a standardized measure that shows the strength and direction of linear relationship between the two variables. In statistics, $\mathrm{r}=-1$ is considered perfect negative correlation, whereas $\mathrm{r}=1$ shows positive correlation. Varying degrees of effect size can be understood by the following matrix:

Effect size of correlation:

$$
\begin{aligned}
& \text { Small } \mathrm{r}=.10 \text { to } .29 ; \\
& \text { Medium } \mathrm{r}=.30 \text { to } .49 \\
& \text { Large } \mathrm{r}=.50 \text { to } 1.0
\end{aligned}
$$

\subsubsection{Pearson Correlation Coefficient}

The following table presents the results of the correlation coefficient test run on the data obtained from the sample selected from three Pakistani universities. The data is about the Social Class of the participants and the Syntax-based Test Score. 
Table 2. Pearson correlation coefficient

\begin{tabular}{llll}
\hline & & Cumulative Class score & Syntax Score \\
\hline \multirow{3}{*}{ Cumulative Class Score } & Pearson Correlation & 1 & $.425^{* *}$ \\
& Sig. (2-tailed) & & .000 \\
& $\mathrm{~N}$ & 82 & 82 \\
\multirow{2}{*}{ Syntax Score } & Pearson Correlation & $.425^{* *}$ & 1 \\
& Sig. (2-tailed) & .000 & 82 \\
\hline **. Correlation is significant at the 0.01 level (2-tailed). & 82 & \\
\hline
\end{tabular}

In the table above, the overall correlation of the total sample is presented. The correlation cut off line or alpha $(\alpha)$ is set to be significant at 0.01 level, and the test statistics reveal $.425^{* *}$ correlation which shows strong correlation between the SC Score and the Syntax test score, as the $1^{\text {st }}$ and the second row in the table show.

$$
\begin{aligned}
& \mathrm{r}=.425 \\
& \alpha=0.01 \\
& \mathrm{r}>\text { alpha }
\end{aligned}
$$

Both the rows in the table present correlation-coefficient of each variable, which means that correlation-coefficient of SC Score with the Syntax score as shown in the first row is .425 , and the correlation-coefficient of Syntax Score with SC Score shown in the second row, is also the same. As the coefficient correlation is always between -1 to +1 , it means that the correlation between the two variables ( $\mathrm{r}$ $=.425)$ can be described as moderately significant.

Second important reading in the table is that of the significance (Sig. (2-tailed). The significance value / cut off line set for this test in SPSS was 0.01 , and according to the test statistics, significance level is .000 , which is lower than the cut off value, and hence, is positive. This means that correlation-coefficient in case of the present test is valid, and did not occur by chance, as would have been the case if the significance value was greater than the cut-off line.

\subsubsection{Scatterplot}

The correlation between the two variables is further explained with the help of the scatterplot to see how a linear relationship occurs between the two variables. A scatterplot shows how one variable occurs in relation to the other variable.

Figure 1 below explains how cumulative class score and syntax test score correlate. With the help of a scatterplot, we can see how the two variables are scattered across the regression line. The line going up is an indication of strong linear relationship, but as to how much strong it is can further be explained by the $\mathrm{r}$ score, which is .425 . This score is neither very high, nor very low and this is the reason why the correlation has been described in the above section as moderately positive, and the relationship, moderately strong.

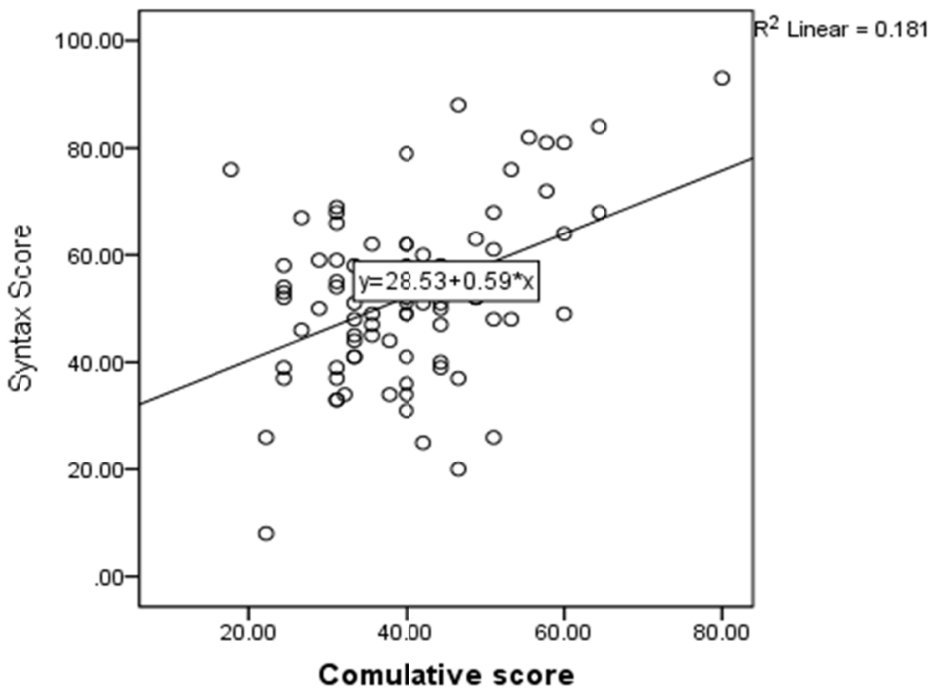

Figure 1. Scatterplot of correlation 
We would need to refer back to the above graph again, when we discuss the regression line; how it is drawn and what it signifies.

\subsubsection{Testing Hypothesis}

The null hypothesis that the current research aimed to test is as below:

There is no correlation between the Social Class Score and the Syntax Score among the sample.

Alternative hypothesis could be as follows:

There is a strong correlation between Social Class Score and the Syntax Score among the sample.

As the results of the correlation reveal positive correlation, the null hypothesis that does not encourage the possibility of a correlation will be rejected in favour of the alternative hypothesis that asserts a strong correlation between the two variables under scrutiny.

\subsubsection{Regression Analysis}

In order to test how much the dependent variable can be explained by the independent variable regression analysis is used. SPSS explains these equations with the help of model summary, which explains the Adjusted $R$ Squared, which, when divided by 100, reveals how much the variance in dependent size can be explained by the independent size. Simply put, it will try to explain as to how much the Syntax score can be explained by the Social Class Score.

Table 3. Model summary

\begin{tabular}{lllll}
\hline Model & $\mathrm{R}$ & $\mathrm{R}$ Square & Adjusted R Square & Std. Error of the Estimate \\
\hline 1 & $.425^{\mathrm{a}}$ & .181 & .170 & 14.61221 \\
\hline a. Predictors: (Constant), Cumulative score & & \\
\hline
\end{tabular}

In the above regression table, Adjusted R Square tells us about the proportion of total variability occurred in the dependent variable explained by the independent variable.

$$
\begin{aligned}
& \mathrm{r} 2 / 100=\text { ratio of predictor } \\
& .170 / 100=17
\end{aligned}
$$

This means that the $17 \%$ variability in the Syntax Score of the subjects can be explained by Social Class of the sample of this study.

\begin{tabular}{|c|c|c|c|c|c|c|}
\hline Model & & Sum of Squares & Df & Mean Square & $\mathrm{F}$ & Sig. \\
\hline & Regression & 3762.932 & 1 & 3762.932 & 17.624 & $.000 \mathrm{~b}$ \\
\hline \multirow[t]{2}{*}{1} & Residual & 17081.324 & 80 & 213.517 & & \\
\hline & Total & 20844.256 & 81 & & & \\
\hline \multicolumn{7}{|c|}{ a. Dependent Variable: Syntax Score } \\
\hline b. Predi & rs: (Constan & ilative score & & & & \\
\hline
\end{tabular}

Table 4. ANOVA ${ }^{\mathrm{a}}$

This table helps us decide the significance of the model, i.e. is the independent variable a good predictor of the dependent variable? This shows as to how much independent variable can be used to explain the dependent variable.

$$
\text { Results: } \mathrm{F}=17.629(1.80)=17.624, \mathrm{P}=.000
$$

\begin{tabular}{|c|c|c|c|c|c|c|}
\hline \multirow[t]{2}{*}{ Model } & & \multicolumn{2}{|c|}{ Unstandardized Coefficients } & \multirow{2}{*}{$\begin{array}{l}\text { Standardized Coefficients } \\
\text { Beta }\end{array}$} & \multirow[t]{2}{*}{$\mathrm{T}$} & \multirow[t]{2}{*}{ Sig. } \\
\hline & & B & Std. Error & & & \\
\hline & (Constant) & 28.530 & 5.861 & & 4.868 & .000 \\
\hline 1 & Cumulative score & .591 & .141 & .425 & 4.198 & .000 \\
\hline
\end{tabular}

As the sig value is .000 , which is less than alpha value $=0.05$, we will conclude that the model is significant.

Table 5. Coefficients ${ }^{\mathrm{a}}$ 
The regression analysis verifies the results of Pearson Correlation Coefficient.

Equation for the line that uses SC Score to predict Syntax Score would take B (intercept value) of the independent variable (.591) and add intercept B value of dependent variable. This gives us:

$$
\mathrm{Y}=.591+28.530
$$

To determine whether the social class is significant, t-value and significance of this table would be read, which are $\mathrm{t}=4.198$ and $\mathrm{Sig}=.000$.

The above analysis reveals that there does exist a moderately significant positive correlation between the independent variable, i.e., social class of the learners and the dependent variable, i.e., their syntax. The former is found to be $17 \%$ responsible for variance in the latter.

\subsection{Findings \& Discussion}

The results of the study bring forward the following salient points as its findings. Firstly, a moderately significant correlation was found among the Social Class core of the sample and the Syntax Score. This is positive and statistically significant correlation as the p-value, i.e., .425 is less than the cut-off point. The p-value being lower than the cut-off point is a proof of the fact that the correlation coefficient is valid and did not occur by chance (Table 2). The second important finding is that of regression analysis according to which $17 \%$ variability in syntax is explained by social class of the sample (Table 3). The third important result is that of Anova which concludes that the model is significant as the significance value is less than alpha value (Table 4).

As has already been discussed in the literature review, Social Class is relevant to the educational attainment of the students as their educational background influences their academic endeavours and students belonging to different social backgrounds are likely to have different performance in their studies. This is also true of the students' performance in language classroom. The results of this study approve the hypothesis that social class of the learners does have a bearing on their performance in the syntax based test. Although it does not mean that their performance in syntax test is in some way influenced by or is a result of their social class, but the same can be explained in terms of correlation, which is a scientific way of putting relationship between the two variables that seem to have some connection with each other. This study confirms Labov's (1996) results (as cited in Callary, 2009) who found out that the five phonological variables that he studied highly correlated with the social class of their informants.

\subsubsection{Syntactic Development and Cognition}

Moving ahead, there feels a need to discuss how the relationship between syntax, which is a component of language, can lead us to the conclusion that cognitive development is social and has something to do with the social background of the learners. In this regard, the studies of Vygotsky (1978) are relevant who thought that all cognitive development happened under the influence of social interaction. This thought is further elaborated in Newman \& Holzman (2005) who cite Vygotsky (1978) as saying that "All the higher mental functions originate as actual relations between people" (p. 62). For Vygotsky, as Ivic (1994) cited, "human being is characterised by primary sociability" (p. 3). He thought that that everything in the behaviours of a child was rooted in social relations, which make the child a truly social being, more than anything else. Linguistic development, then, is as much to be considered cognitive as it is to be considered social, since no cognitive development, and hence, no linguistic development is possible without social interaction of the learner with the society he lives in. Society, in turn, has its impact on what he is, who he wants to be, and how he appears to others through his interaction, which, of course, happens through the language he uses.

\section{Conclusion}

The study tried to find out correlation between the social class of the learners and their syntactic development. It aimed to explore what is the correlation between both social and linguistic variable and intended to highlight that language being a cognitive phenomenon is not free from social influences. In doing so, the researcher collected data from the sample selected from three universities of Islamabad who were EFL learners. They were given social class proforma to fill out, and their social class score was calculated according to the index (SEI) prepared for this purpose. A test based on various areas of syntax was designed to measure their syntactic development. The sample's Social Class score and the Syntax score was studied for correlation. SPSS revealed a moderately significant positive correlation between social class and syntax. Since language in general and syntax in particular are considered to be developing in cognition, the study concluded that there does exist a relationship between social class of the EFL learners and their cognitive development of syntax, as proved by the results of the study. 
The study could be useful in understanding the dynamics of Pakistani classrooms where English is taught as a foreign language. It is not only a theoretically based study, but also has practical implication in ELT context within Pakistan. Pakistan is a multi-class society in which people from different strata of society are seen to be competing with each other in order to attain better social ranking within the society. However, social background of the individuals is a key factor in their general life achievements, with academic arena being no exception. There is some useful insight to be gained through the conclusions of this study which suggest varied performance among the learners under the influence of their social background. Higher social background of the participants of this study apparently provides them favourable circumstances, which help them lead the way in their competition with others, and those with lower social background are likely to be on the losing side due to being lesser advantaged in the society. The social advantage or disadvantage, then, seems to perpetuate in the society due to there being little equal opportunity for all and sundry and unequal chances of progress. This social disparity is a point to ponder not only for the academics but also for those in power, whose ultimate goal should be to provide equal opportunities of progress to all citizens, no matter what strata of society they might belong to.

\section{References}

Al-Jasser, J. A. (2012). Psycholinguistic theories of language acquisition and the Saudi learner of English. Retrieved from http://www.google.co.uk/url?sa=t\&rct=j\&q=definition\%20of\%20language $\% 20 \mathrm{in} \% 20$ psycholinguistics\&so urce $=$ web\&cd.......

Botha, W. (2011). Dimensions in variationist sociolinguistics: A sociolinguistic investigation of language variation in Macau. Master of Arts with Specialisation of Scoiolinguistics thesis, University of South Africa. Retrieved from http://uir.unisa.ac.za/bitstream/handle/10500/5724/thesis_botha_w.pdf?sequence=1

Büchner, C., Velden, R. V. D., \& Wolbers, M. (2012). Educational achievement and social origin—an investigation of primary and secondary effects of social stratification over four Dutch cohorts. Retrieved from http://www.socsci.ru.nl/ maartenw/S3_P3_B\%C3\%BCchner.pdf

Callary, R. (1974). Status perception through syntax. Language and Speech, 17, 187-192. https://doi.org/10.1177/002383097401700211

Callary, R. (2009). Syntax and social class. Linguistics, 13(143), 5-16.

Cheshire, J. (2015). Age and generation-specific use of language. Queen Mary University of London. Retrieved June 4, 2016, from www.webspace.qmul.ac.uk

Chomsky, N. (1953). Systems of syntactic analysis. The Journal of Symbolic Logic, 18(3), 242-256. https://doi.org/10.2307/2267409

Christiansen, G., \& Dirven, R. (2008). Cognitive sociolinguistics: Rationale, methods and scope. In G. Christiansen \& R. Dirven (Eds.), Cognitive Sociolinguistics: Language Variation, Cultural Models, Social Systems. Berlin, New York: Mouton de Gruyter. https://doi.org/10.1515/9783110199154.0.1

Coloma, G., \& Aires, B. (2010). An econometric method to detect the social significance of linguistic variables. GLOTTOTHEORY, 3(2), 9-21. https://doi.org/10.1515/glot-2010-0011

Condor, S., \& Antaki, C. (2010). Social cognition and discourse. In T. A. Van Dijk (Ed.), Discourse as structure and process (p. 320). London: Sage Publications.

Hruschka, D. J. et al. (2009). Building social cognitive models of language change. Trends in Cognitive Science, 13(11). https://doi.org/10.1016/j.tics.2009.08.008

Halliday, M. A. K. (2007). Language and society. London, New York: Continuum.

Howard, J. A., \& Renfrow, D. G. (2006). Social cognition (pp. 259-281).

Ivic, I. (1994). Lev S. Vygotsky. Prospects: The Quarterly Review of Comparative Education. Paris, UNESCO: International Bureau of Education, XXIV(3/4), 471-485. OUNESCO: International Bureau of Education, 2000.

Johnson, S. P. (2010). Neoconstructivism: The new science of cognitive development. Oxford: Oxford University Press.

Juchem, M. (2003). W. Labov: Case Study Martha's Vineyard and New York. Sprachwissenschaft Englisch Hausarbeit. Sociolinguistics. Retrieved from http://www.maria-juchem.de/Labov.PDF 
Labov, W. (1960). Language and social class. Retrieved from www.jstor.com

Labov, W. (1964). Phonological correlates of social stratification. American Anthropologist, 66(6). https://doi.org/10.1525/aa.1964.66.suppl_3.02a00120

Labov, W. (1972). The social stratification of / r/ in New York departmental stores. Sociolinguistics. University of Pennsylvania. Philadelphia. Retrieved from https://www.sciencedirect.com/science/article/pii/B978012051130350029X

Lock, A., \& Strong, T. (2010). Social constructionism: Sources and stirrings in theory and practice. Cambridge: Cambridge University Press. https://doi.org/10.1017/CBO9780511815454

Mallinson, C. (2007). Social class, social status and stratification: Revisiting familiar concepts in Sociolinguistics. Retrieved from https://pdfs.semanticscholar.org/41bc/235ad22812300fbf434613a6424efd5ae431.pdf

Marton, K., Abramoff, B., \& Rosenzweig, S. (2009). Social cognition and language in children with specific language impairment (SLI). Journal of Communication Disorders, 38, 143-162. https://doi.org/10.1016/j.jcomdis.2004.06.003

Mather, P. A. (2011). The social stratification of /r/ in New York city: Labov's department store study revisited. Journal of English Linguistics. Retrieved from http://pamather.com/yahoo_site_admin1/assets/docs/Journal_of_English_Linguistics-2011-Mather-0075424 211431265.94212647.pdf

Newman, F., \& Holzman, L. (2005). Lev Vygotsky: Revolutionary scientist. Retrieved from simbi.kemenag.go.id/pustaka/images/materibuku/revolutionary-scientist.pdf

Neisser, U. (2009). Cognitive psychology, Grolier multimedia encyclopedia. Retrieved from http://gme.grolier.com.ccnyproxy1.libr.ccny.cuny.edu/cgi-bin/article?assetid=0066790-0

Olsen, K. R., \& Dweck, C. S. (2008). A blueprint for social cognitive development. Perspectives on Psychological Science, 3(3), 193-202. https://doi.org/10.1111/j.1745-6924.2008.00074.x

Payne, B. K., \& Gawronski, B. (n. d). A history of implicit social cognition: Where is it coming from? Where is it now? Where is it going? Retrieved from https://www.researchgate.net/profile/Brian_Payne4/publication/267974828_A_History_of_Implicit_Social_ Cognition_Where_Is_It_Coming_From_Where_Is_It_Now_Where_Is_It_Going/links/5506 d9ab0cf $2 \mathrm{~d} 7 \mathrm{a} 28$

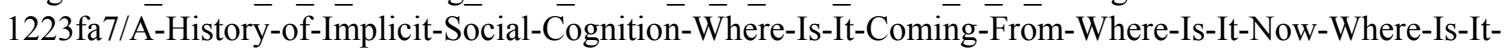
Going.pdf

Rahimpour, M. (2010). Cognitive development and language acquisition. In L. ScLiar-cabra (Ed.), Psycholinguistics: Scientific and technological challenges (p. 189). Porto Alegre: EDIPUCRS. Retrieved from

https://books.google.co.uk/books?hl=en\&lr=\&id=sHBMEL2r1TAC\&oi=fnd\&pg=PA189\&dq=Rahimpour, + M. $+(2010) .+$ Cognitive + development + and + language + acquisition.\&ots $=M e 1 \mathrm{C} \_$i8PPx\&sig $=94 \mathrm{GmrGsN50o}$ Xhq1ZbHjUl1_sqxg\#v=onepage\&q\&f=false

Reardon, S. F. (2011). The widening academic achievement gap between the rich and the poor: New evidence and possible explanations. Stanford University. Retrieved from http://cepa.stanford.edu/sites/default/files/reardon\%20whither\%20opportunity\%20-\%20chapter\%205.pdf

Serrano, M. J. (1998). On the variability of syntax: some theoretical remarks. Retrieved from www.phon.ucl.ac.uk/home/dick/papers/texts/dialect-syntax.pdf

Vasilyeva, M. Waterfall, H., \& Huttenlocher, J. (2008). Emergence of syntax: Commonalities and differences across children. https://doi:10.1111/j.1467-7687.2007.00656.x

Willingham, D. T. (2012). Why does family wealth affect learning. American Educator, Spring 2012. Retrieved from www.aft.org/pdfs/americaneducator/spring2012/Willingham.pdf

Wilkins, D. A. (1974). Linguistics in language teaching. London: Edward Arnold. 


\section{Copyrights}

Copyright for this article is retained by the author(s), with first publication rights granted to the journal.

This is an open-access article distributed under the terms and conditions of the Creative Commons Attribution license (http://creativecommons.org/licenses/by/4.0/). 